\title{
Nature of the inhibition layer in GA baths *
}

\author{
D. Zapico Álvarez ${ }^{1,2}$, F. Bertrand ${ }^{1}$, J.-M. Mataigne ${ }^{1}$ and M.-L. Giorgi ${ }^{2}$ \\ 1 ArcelorMittal Global R\&D - Automotive Products Centre, Voie Romaine BP 30320, \\ 57283 Maizières-Lès-Metz, France \\ e-mail: jean-michel.mataigne@arcelormittal.com \\ 2 École Centrale Paris, Grande Voie des Vignes, 92295 Châtenay-Malabry Cedex, France
}

Key words:

hot-dipping; solid/liquid interface; intermetallic compounds; inhibition layer; galvannealed coating

Received 6 December 2013 Accepted 22 January 2014

\begin{abstract}
The nature of the intermetallic layer which forms on the steel surface during immersion in typical galvanizing baths for galvannealed (GA) sheets production has been investigated on two commercial Titanium-stabilized Interstitial-Free (Ti-IF) steel substrates galvanized in baths with different Al contents. Results from this study show that in both cases the inhibition layer is biphasic and composed of a very thin Al-rich phase layer, identified as $\mathrm{Fe}_{2} \mathrm{Al}_{5} \mathrm{Zn}_{x}$, and a thicker $\mathrm{Zn}$-rich phase layer on top of it, identified as $\delta$. Experimental results also show that the $\mathrm{Fe}_{2} \mathrm{Al}_{5} \mathrm{Zn}_{x}$ phase layer becomes discontinuous when decreasing the bath Al content. Discussions about the mechanisms of formation and the final microstructure of this inhibiting layer are also tackled in this paper by means of the Al-Fe-Zn ternary phase diagram at $460^{\circ} \mathrm{C}$ and assumptions to justify any deviation from thermodynamic equilibrium are as well proposed.
\end{abstract}

\section{Introduction}

As well known, a thin layer of intermetallic compounds, usually called inhibition layer, is formed on the steel surface in the earlier moments of immersion in GA baths (Fesaturated $\mathrm{Zn}$ baths with $\mathrm{Al}$ content ranging from 0.10 to $0.135 \mathrm{wt} . \%$ at $460{ }^{\circ} \mathrm{C}$ ). The nature of this inhibition layer is still a subject of controversy. According to the Al-Fe- $\mathrm{Zn}$ phase diagram [1], this layer is expected to be composed of the $\delta$ phase only. Nucleation of this phase on the steel surface would allow the system to reach the thermodynamic equilibrium along both newly created interfaces. However, very few researchers support these thermodynamic predictions [2-4]. According to various studies, the inhibition layer was found to be mainly composed of metastable $\mathrm{Fe}_{2} \mathrm{Al}_{5} \mathrm{Zn}_{x}$ [5-10]. Some of them have even reported the transient presence of other metastable phases, such as $\mathrm{FeAl}_{3}[6,7,9]$ and $\mathrm{FeAl}_{2}$ [7], in coexistence with $\mathrm{Fe}_{2} \mathrm{Al}_{5} \mathrm{Zn}_{x}$. A biphasic interfacial layer composed of $\mathrm{Fe}_{2} \mathrm{Al}_{5} \mathrm{Zn}_{x}$ with $\delta$ on its

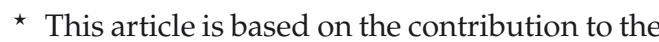
9th International Conference on Zinc and Zinc Alloy Coated Steel Sheet (GALVATECH 2013). top has also been proposed in two cases: in liquid phase supposed to be in equilibrium with $\delta$ [11] or in equilibrium with $\delta$ and $\mathrm{Fe}_{2} \mathrm{Al}_{5} \mathrm{Zn}_{x}$ [12]. Nevertheless, no solid experimental evidence goes along with these communications in most cases. The aim of the present study is therefore to investigate the nature of this inhibiting layer.

\section{Experimental procedure}

\subsection{Materials}

Two commercial Ti-IF steel samples A and B, galvanized in industrial baths with different $\mathrm{Al}$ contents $(0.112$ and 0.128 wt.\% $\mathrm{Al})$, have been selected for this study. The decision to choose industrial samples lies in the interest of identifying possible differences in the nature of the inhibition layer formed in GA baths for different real industrial conditions (i.e., temperature and composition of the bath, hydrodynamic conditions). The chemical composition of steels A and B is presented in Table 1. The analysis was performed by means of Spark-Optical Emission Spectrometry (Spark-OES) and Combustion 
Table 1. Average chemical composition $\left(\times 10^{-3} \mathrm{wt} . \%\right)$ of the two commercial Ti-IF steels studied.

\begin{tabular}{cccccccccccccccc}
\hline Steel & $\mathrm{C}$ & $\mathrm{Mn}$ & $\mathrm{P}$ & $\mathrm{S}$ & $\mathrm{N}$ & $\mathrm{Si}$ & $\mathrm{Cu}$ & $\mathrm{Ni}$ & $\mathrm{Cr}$ & $\mathrm{Sn}$ & $\mathrm{Nb}$ & $\mathrm{Mo}$ & $\mathrm{B}$ & $\mathrm{Ti}$ & $\mathrm{Al}$ \\
\hline $\mathrm{A}$ & 1.6 & 103 & 11.0 & 6.0 & 3.4 & 9.0 & 13.0 & 17.0 & 14.0 & 2.0 & $<2.0$ & $<2.0$ & $<0.3$ & 53.0 & 39.0 \\
$\mathrm{~B}$ & 2.7 & 113 & 9.0 & 8.0 & 2.3 & 4.0 & 18.0 & 14.0 & 20.0 & 6.0 & $<2.0$ & 2.0 & $<0.3$ & 67.0 & 46.0 \\
\hline
\end{tabular}

Table 2. Galvanizing process data for both steels.

\begin{tabular}{cccccc}
\hline Steel & $v(\mathrm{~m} / \mathrm{min})^{\mathrm{a}}$ & $w_{\mathrm{Al}}(\mathrm{wt} . \%)^{\mathrm{b}}$ & $T_{\text {bath }}\left({ }^{\circ} \mathrm{C}\right)^{\mathrm{c}}$ & $L_{i m}(\mathrm{~m})^{\mathrm{d}}$ & $t_{i m}(\mathrm{~s})^{\mathrm{e}}$ \\
\hline $\mathrm{A}$ & 120 & 0.112 & 450 & 2.7 & 1.4 \\
$\mathrm{~B}$ & 130 & 0.128 & 460 & 4.0 & 1.9 \\
\hline bath Al content; ${ }^{\mathrm{c}}$ bath temperature; ${ }^{\mathrm{d}}$ immersion length; ${ }^{\mathrm{e}} t_{\text {im }}=L_{\text {im }} / v$.
\end{tabular}

${ }^{\mathrm{a}}$ Line speed; ${ }^{\mathrm{b}}$ bath $\mathrm{Al}$ content; ${ }^{\mathrm{c}}$ bath temperature; ${ }^{\mathrm{d}}$ immersion length; ${ }^{\mathrm{e}} t_{i m}=L_{i m} / v$.

and Infrared Detection for $\mathrm{N}$ in ArcelorMittal laboratories. The galvanizing process data for these steels are available in Table 2. In both cases, the galvannealing furnace was off-line in order to prevent Fe-Zn alloying reactions, so that the studied microstructures are supposed to be a representative result of the phenomena taking place in the GA bath.

\subsection{Techniques}

First, the general structure of the inhibition layer was characterized through a controlled selective electrochemical dissolution protocol coupled with energy dispersive spectroscopy (EDS) surface analysis in a Scanning Electron Microscope (SEM, LEO $D S M$ 982). The dissolution protocol consisted in removing either $\mathrm{Zn}$ or both $\mathrm{Zn}$ and Fe-Zn compounds. In parallel, cross section samples were prepared through Ar ion beam cross section polishing (CSP, JEOL SM09010) and characterized by EDS in SEM (JEOL JSM-7001F).

In order to determine the nature of the phases present in the inhibition layer, Focused Ion Beam (FIB, SII Nanotechnology Inc SMI 3050TB) thin foils (Fig. 1) were carefully prepared from samples after selective removal of the Zn overlay and analysed by EDS and Electron Diffraction in a Transmission Electron Microscope (TEM, JEOL JEM2100F).

In addition to the FIB foils, thin films extracted from the surface of the samples after selective dissolution of $\mathrm{Zn}$ and Fe-Zn phases were also characterized in TEM. The extraction protocol used consisted in depositing a thin carbon film on the surface of the sample and dipping it into a $10 \mathrm{vol} \%$ aqueous solution of $\mathrm{HNO}_{3}$. Prior to the dipping, the

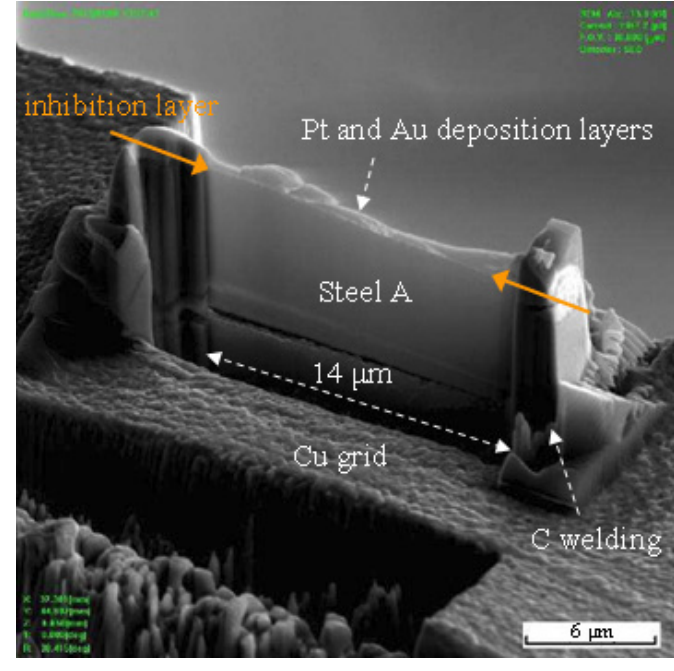

Fig. 1. FIB thin foil extracted from steel A prepared after electrochemical dissolution of the $\mathrm{Zn}$ coating (Au and Pt surface depositions have been carried out after $\mathrm{Zn}$ removal for conductivity and protection reasons respectively).

carbon film was scarified in order to make the acid solution penetrate between the steel surface and the intermetallic layer. The steel in contact with the acid solution was dissolved, causing the separation from the steel matrix of the intermetallic layer embedded into the carbon film. Floating carbon films were then rapidly collected at the surface of the solution, rinsed with ethanol and transferred onto $\mathrm{Cu}$ grids for TEM observations.

\section{Results}

\subsection{General structure of the inhibition layer}

The potential $(E)$ against time $(t)$ electrochemical curve obtained on sample B (blue 

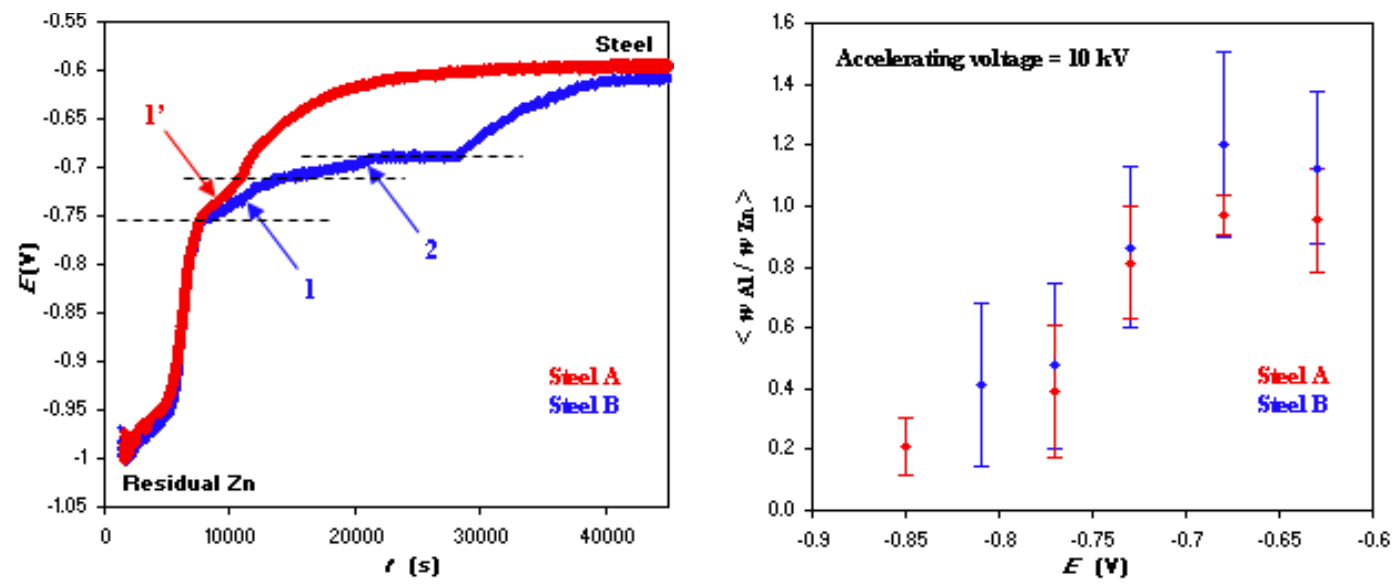

Fig. 2. Measured potential $(E)$ against time $(t)$ electrochemical curves (left) and average Al/Zn mass ratio $\left(\left\langle w_{\mathrm{Al}} / w_{\mathrm{Zn}}\right\rangle\right)$ against imposed potential $(E)$ (right) for steels $\mathrm{A}$ and $\mathrm{B}(\mathrm{X}$-ray energies of lines $\mathrm{K} \alpha$ for $\mathrm{Al}$ and $\mathrm{L} \alpha$ for $\mathrm{Zn}$ used for EDS quantification).
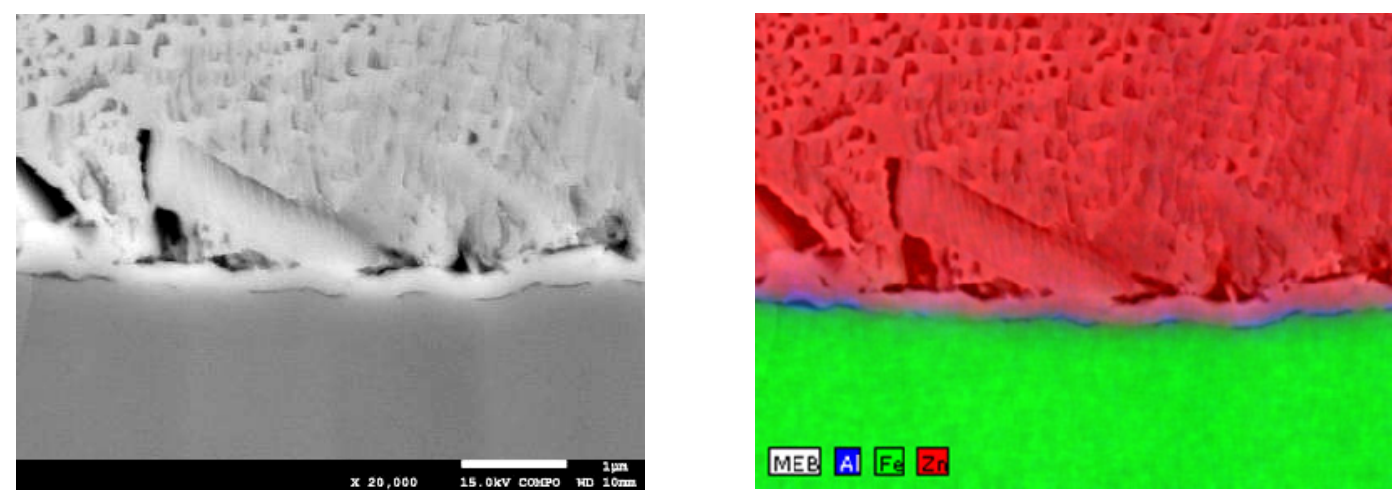

Fig. 3. Cross-section micrograph (left) and EDS element mapping (right) of the inhibition layer (CSP sample from steel A).

curve in Fig. 2 left) suggests that the inhibition layer is composed of two different phase layers as two different dissolution stages (arrows 1 and 2) can be easily differentiated between the residual $\mathrm{Zn}$ (most of the $\mathrm{Zn}$ coating had been previously removed) and the steel matrix. In the case of sample A (red curve in Fig. 2 left), only the dissolution stage corresponding to the phase layer in direct contact with $\mathrm{Zn}$ can be identified (arrow 1').

EDS surface analysis in SEM after surface electrochemical dissolution at different imposed potentials, corresponding to those of the inhibition layer, is shown in Figure 2 right. Two different $\mathrm{Al} / \mathrm{Zn}$ mass ratio populations can be easily distinguished in both cases depending on the imposed potential.
It can be deduced from these results that the inhibition layer is composed of two different phases, the one in direct contact with the steel having a higher $\mathrm{Al} / \mathrm{Zn}$ mass ratio than the one on its top.

The previous information can be confirmed by SEM results on CSP samples from steels A (Fig. 3) and B (Fig. 4): the inhibition layer is in both cases composed of a very thin Al-rich phase layer and a thicker $\mathrm{Zn}$-rich phase layer on top of it. It is also important to highlight that the Al-rich layer is discontinuous in the case of steel $\mathrm{A}$ and continuous in the case of steel B. This observation, evidenced in the whole length of the CSP samples (425 and $275 \mu \mathrm{m}$ for samples A and B respectively), could explain 

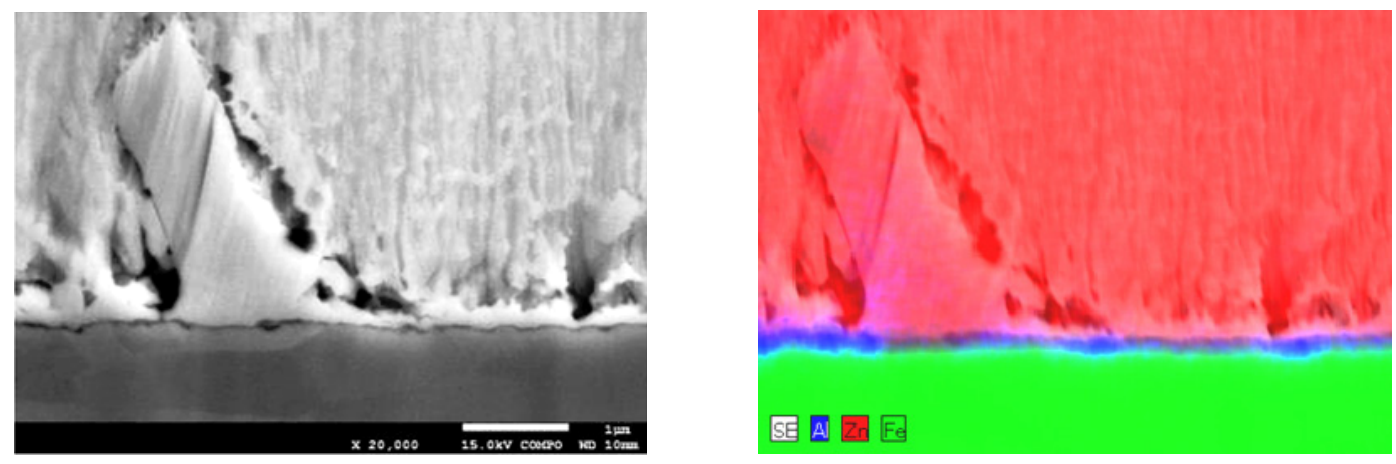

Fig. 4. Cross-section micrograph (left) and EDS element mapping (right) of the inhibition layer (CSP sample from steel B).

the differences observed in the shape of the electrochemical curves from Figure 2 left. In addition, other crystals have been seldom found in the CSP samples. These crystals have not been investigated here but they are supposed to be $\zeta$ crystals, based on their rod shape $[2-4,12-14]$. They can be formed either in the bath in epitaxic relationships with ferrite $[3,13,14]$ or during the solidification of the coating as randomly orientated crystals $[2,4,12]$.

\subsection{Inhibition layer phase identification}

Results from TEM analysis on the Zn-rich phase of the FIB foil extracted from steel B are summarized in Figure 5. EDS analysis on this phase (Fig. 5 left) is consistent with the composition found in the literature for the $\delta$ phase (2.8 wt. \% Al, 9.0 wt.\% Fe and 88.2 wt. $\%$ Zn [15]. The obtained Electron Diffraction pattern has been compared with the one calculated from the $\delta$ phase JCPDS file \#45-1186 (hexagonal lattice, space group $\mathrm{P}$, lattice parameters $a=b=1.28 \mathrm{~nm}, c=5.76 \mathrm{~nm}$ ) and it can be confirmed that the Zn-rich phase corresponds to the $\delta$ phase (Fig. 5 right).

The identification of the Al-rich phase was not possible on the FIB cuts. The chemical composition of this phase given by EDS analysis recorded on the FIB cut was 38.5 wt. $\%$ Al, 36.9 wt. $\%$ Fe and 24.6 wt. $\%$ Zn, close to the one found in the literature for $\mathrm{Fe}_{2} \mathrm{Al}_{5} \mathrm{Zn}_{x}$ (43.1 wt.\% Al, $36.0 \mathrm{wt} . \% \mathrm{Fe}$ and 20.9 wt.\% Zn [15]. However, the indexation of the Electron Diffraction pattern obtained for this Al-rich layer was not possible because its quality was not good enough.

In order to achieve the identification of the Al-rich phase, films of this phase extracted from selectively dissolved samples of steel B were analysed in TEM. The obtained results are summarized in Figure 6. EDS analysis on this phase (Fig. 6 left) is close to the composition found in the literature for $\mathrm{Fe}_{2} \mathrm{Al}_{5} \mathrm{Zn}_{x}$ [15]. The Electron Diffraction pattern recorded for this phase is compared to the one calculated from the $\mathrm{Fe}_{2} \mathrm{Al}_{5} \mathrm{Zn}_{x}$ JCPDS file \#049-1381 (orthorhombic, space group $\mathrm{Cmcm}$, lattice parameters $a=0.7656 \mathrm{~nm}, b=0.6404 \mathrm{~nm}, c=0.4241 \mathrm{~nm}$ ) after slight adjustment of the lattice parameters $(a=0.767 \mathrm{~nm}, b=0.641 \mathrm{~nm}, c=$ $0.424 \mathrm{~nm}$ ). This allows confirming that the Al-rich phase present in the inhibition layer is the $\mathrm{Fe}_{2} \mathrm{Al}_{5} \mathrm{Zn}_{x}$ phase (Fig. 6 right).

It should be noted that similar results have been obtained on the FIB foil extracted from steel A.

\section{Discussions}

Concerning the mechanism of formation of the inhibition layer, the question about which phase between $\mathrm{Fe}_{2} \mathrm{Al}_{5} \mathrm{Zn}_{x}$ and $\delta$ nucleates first cannot be undoubtedly answered yet. However, observations on the CSP sample from steel A, for which $\mathrm{Fe}_{2} \mathrm{Al}_{5} \mathrm{Zn}_{x}$ is discontinuous, encourage thinking that it is this phase which nucleates first. As can be seen in Figure 7, several "holes" along the steel/inhibition layer interface are present on those zones were 

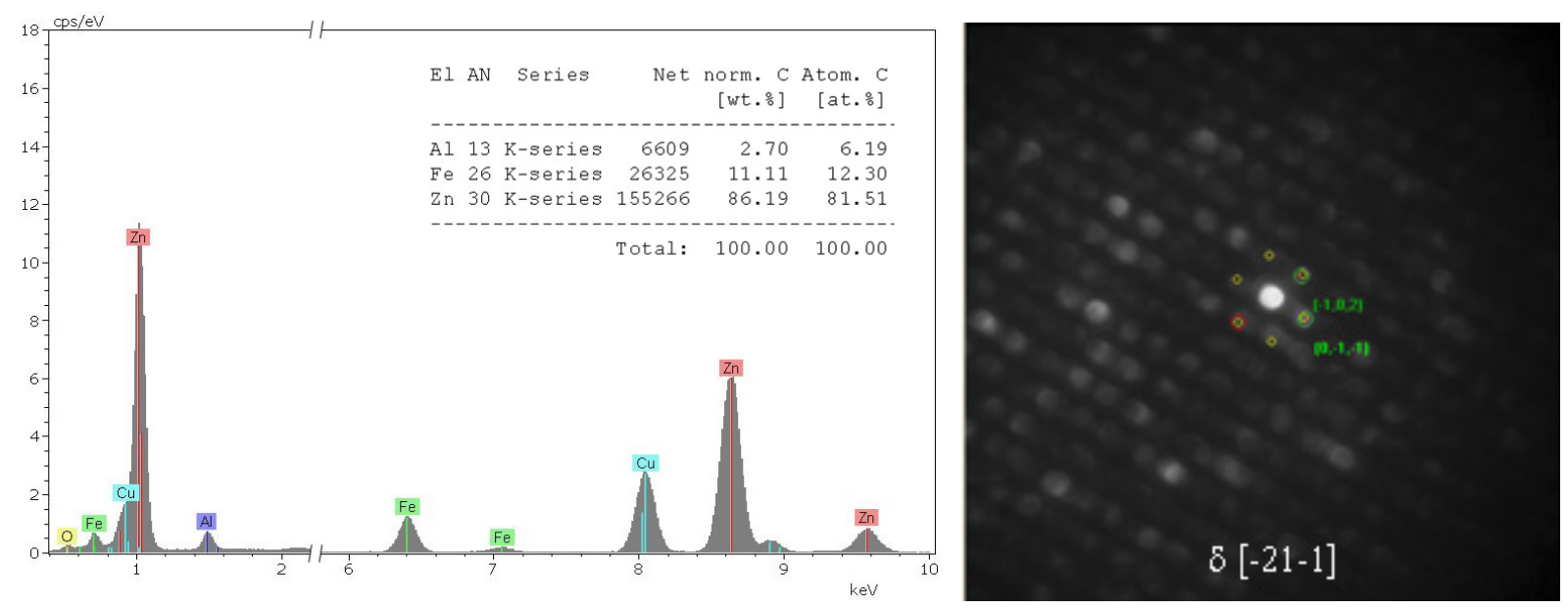

Fig. 5. EDS spectrum (left) and diffraction pattern (right) of the Zn-rich phase of the inhibition layer (FIB foil from steel B).
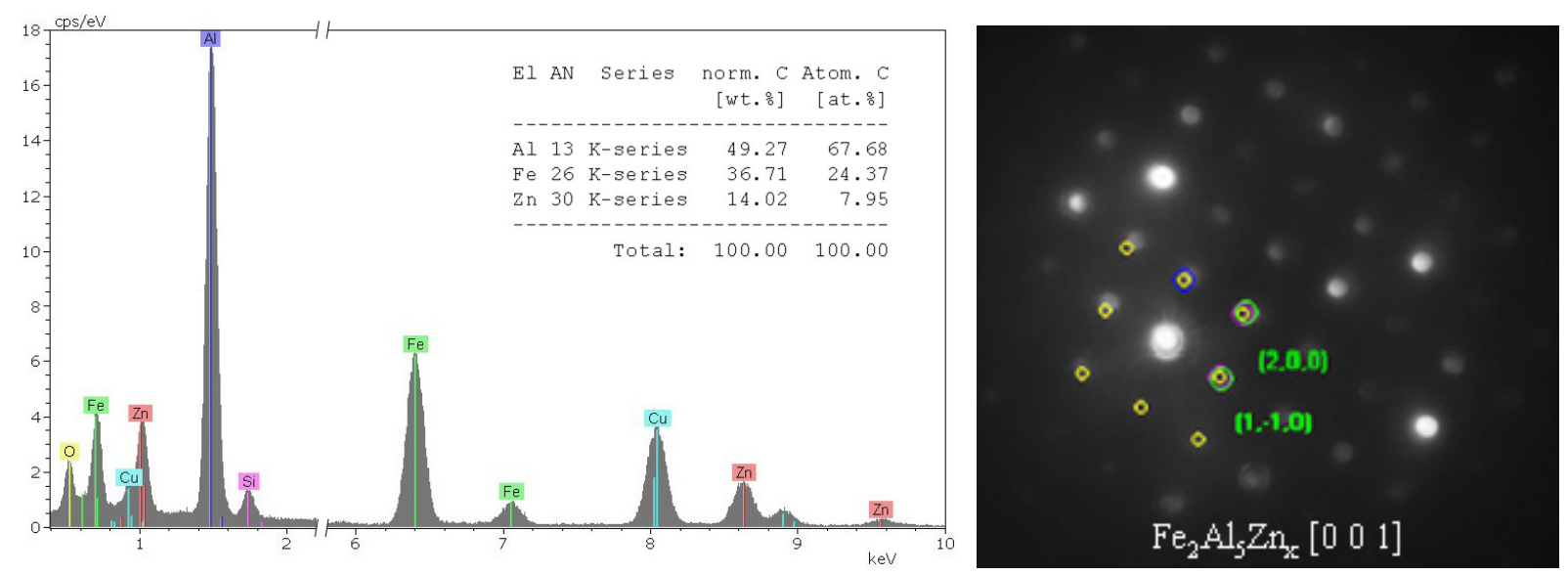

Fig. 6. EDS spectrum (left) and diffraction pattern (right) of the Al-rich phase of the inhibition layer (films from steel B).

$\mathrm{Fe}_{2} \mathrm{Al}_{5} \mathrm{Zn}_{x}$ is not present. Assumption to explain this observation is that metastable $\mathrm{Fe}_{2} \mathrm{Al}_{5} \mathrm{Zn}_{x}$ would nucleate discontinuously on the steel surface. The Fe dissolution process would therefore be blocked on those zones were $\mathrm{Fe}_{2} \mathrm{Al}_{5} \mathrm{Zn}_{x}$ has nucleated while it would proceed in the adjoining areas leading to the observed "holes" which would be then occupied by the subsequent nucleation of the $\delta$ phase. The reason why metastable $\mathrm{Fe}_{2} \mathrm{Al}_{5} \mathrm{Zn}_{x}$ nucleates at the steel/liquid $\mathrm{Zn}$ interface, instead of stable $\delta$, is likely due to epitaxic relationships between $\mathrm{Fe}_{2} \mathrm{Al}_{5} \mathrm{Zn}_{x}$ and the ferrite, already reported by different authors $[5,6,16]$.
The final microstructure of the inhibition layer in GA baths can be described by means of the concept of diffusion path in the Al-FeZn ternary phase diagram at $460{ }^{\circ} \mathrm{C}$ [2-4] as depicted in Figure 8. In steel B, the inhibition layer microstructure consists of successive continuous intermetallic layers with planar interfaces (Fig. 4): $\mathrm{Fe} / \mathrm{Fe}_{2} \mathrm{Al}_{5} \mathrm{Zn}_{x} / \delta / \mathrm{Zn}$ overlay. Assuming thermodynamic equilibrium along all interfaces, this microstructure can be represented by the real (along tie lines through binary domains) diffusion path \#1 in Figure 8. In steel $\mathrm{A}$, the $\mathrm{Fe}_{2} \mathrm{Al}_{5} \mathrm{Zn}_{x}$ layer is discontinuous: the successive layers can be locally either $\mathrm{Fe} / \mathrm{Fe}_{2} \mathrm{Al}_{5} \mathrm{Zn}_{x} / \delta / \mathrm{Zn}$ or $\mathrm{Fe} / \delta / \mathrm{Zn}$. 


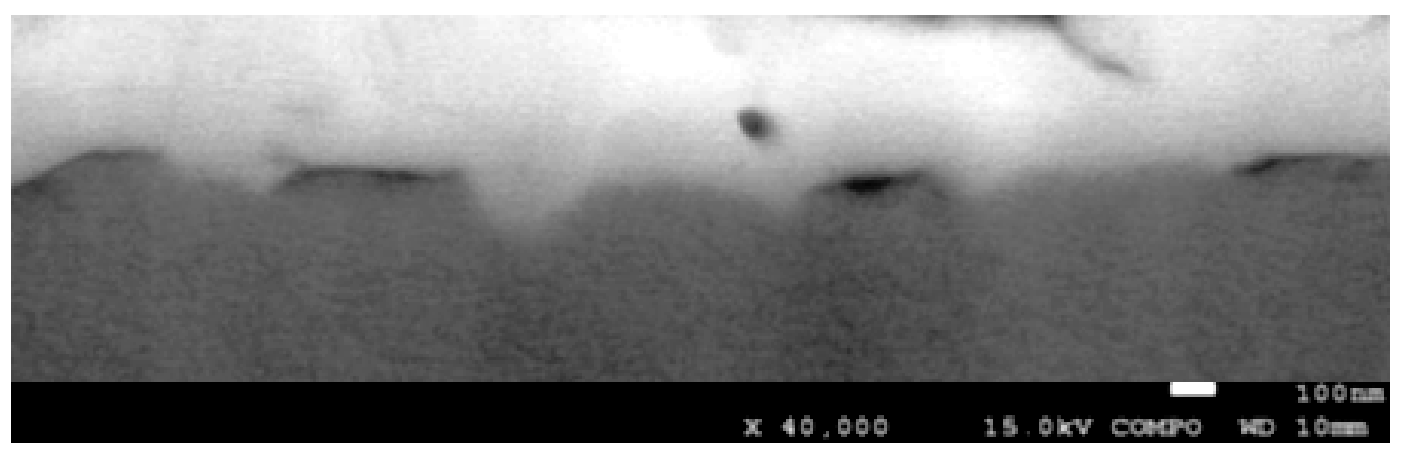

Fig. 7. Illustration of Fe dissolution on the zones where $\mathrm{Fe}_{2} \mathrm{Al}_{5} \mathrm{Zn}_{x}$ has not nucleated (presence of "holes"), followed by subsequent nucleation of $\delta$ (CSP sample from steel A).

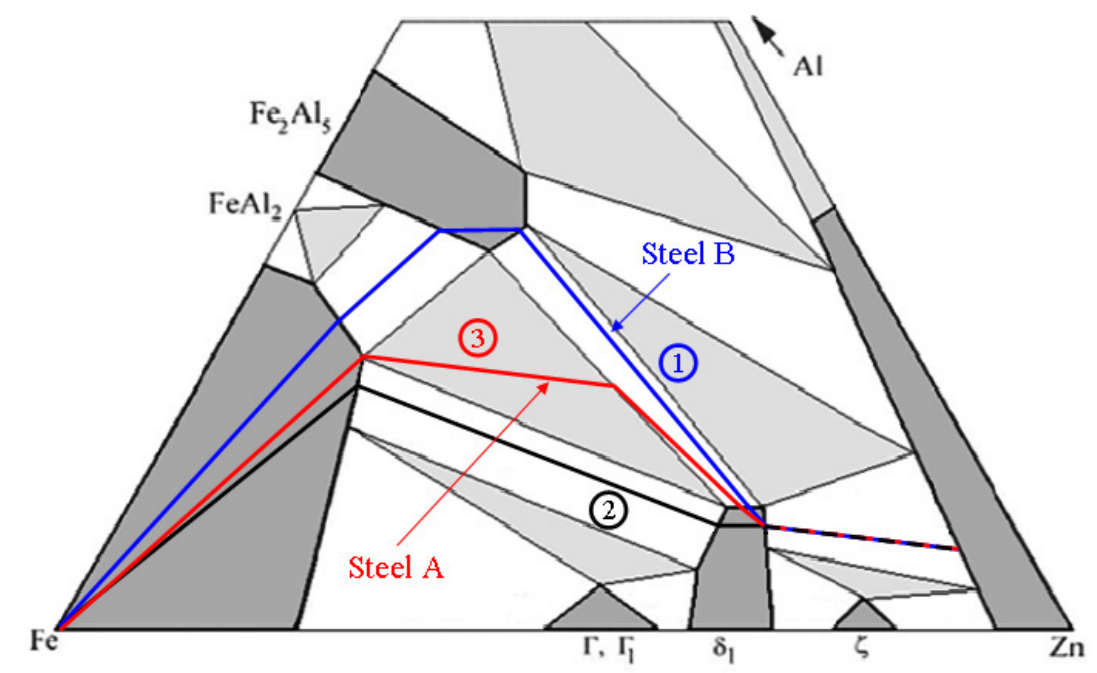

Fig. 8. Schematic diffusion paths illustrating the formation of the inhibition layer in GA baths represented on a schematic view of the $\mathrm{Zn}$-rich corner of $\mathrm{Al}-\mathrm{Fe}-\mathrm{Zn}$ ternary phase at $460{ }^{\circ} \mathrm{C}$.

Each of these local microstructures can be represented by real diffusion paths \#1 and \#2 in Figure 8. The global diffusion path corresponding to steel A can be represented by the virtual diffusion path \#3. Equilibrium along the steel surface is therefore a ternary equilibrium $\left(\mathrm{Fe}, \delta, \mathrm{Fe}_{2} \mathrm{Al}_{5} \mathrm{Zn}_{x}\right.$ ). The nucleation and growth of the $\delta$ phase allows all the interfaces to reach thermodynamic equilibrium, temporarily stabilizing the inhibition layer.

\section{Conclusions}

(1) The inhibition layer which forms in GA baths is biphasic and composed of a very thin layer of $\mathrm{Fe}_{2} \mathrm{Al}_{5} \mathrm{Zn}_{x}$ and a thicker layer of $\delta$ on top of it. Both observed microstructures (with continuous or discontinuous $\mathrm{Fe}_{2} \mathrm{Al}_{5} \mathrm{Zn}_{x}$ ) allow thermodynamic equilibrium to be reached along all the interfaces and can be described by diffusion paths in the AlFe-Zn ternary phase diagram at $460{ }^{\circ} \mathrm{C}$.

(2) Proposed mechanism accounting for the formation of this inhibiting layer can be summarized in the following steps: Fe dissolution, Fe supersaturation at the steel/liquid $\mathrm{Zn}$ interface, nucleation of metastable $\mathrm{Fe}_{2} \mathrm{Al}_{5} \mathrm{Zn}_{x}$, assumed to be due to epitaxial relationships with the ferrite, and nucleation and growth of $\delta$, which allow the interfaces of the final microstructure of the inhibition layer to reach thermodynamic equilibrium.

(3) The thin layer of $\mathrm{Fe}_{2} \mathrm{Al}_{5} \mathrm{Zn}_{x}$ becomes discontinuous when decreasing the bath 
Al content. Assumption to explain this observation is that as the bath $\mathrm{Al}$ content is decreased, the metastability of $\mathrm{Fe}_{2} \mathrm{Al}_{5} \mathrm{Zn}_{x}$ becomes higher and its nucleation less probable.

\section{Acknowledgements}

The authors are extremely grateful to Céline Musik and Patrick Barges for their work on CSP sample preparation and SEM and TEM analysis. The authors also thank Annick Willems for her valuable assistance in the FIB foils preparation.

\section{References}

[1] N.Y. Tang, J. Phase Equilibria 21 (2000) 70-77

[2] Y. Leprêtre, J.M. Mataigne, M. Guttmann, J. Philibert, Reactive interdiffusion in the FeAl-Zn system: Reaction mechanisms during hot-dip galvanizing, F.E. Goodwin ed., ZincBased Steel Coating Systems: Production and Performance. USA The Minerals, Metals \& Materials Society, 1998, pp. 95-106

[3] J.M. Mataigne, Rev. Métall. 106 (2009) 27-33

[4] Y. Leprêtre, Étude des mécanismes réactionnels de la galvanisation, Ph.D Thesis, Université Paris XI Orsay, 1996 (in French)
[5] M. Guttmann, Mat. Sci. Forum 155/156 (1994) 527-548

[6] L. Chen, R. Fourmentin, J.R. McDermid, Metall Mater Trans. A 39 (2008) 2128-2142

[7] M. Úředniček, J.S. Kirkaldy, Z. Met. kd. 64 (1973) 899-910

[8] M. Saito, Y. Uchida, T. Kittaka, Y. Hirose, Y. Hisamatsu, Tetsu-to-Hagané 77 (1991) 947954 (in Japanese)

[9] M. Sugiyama, M. Okada, Y. Takada, M. Suehiro, J. Japan Inst. Met. 65 (2001) 397-402 (in Japanese)

[10] A.I. Vitkin, G.A. Kokorin, A.G. Grishko, P.A. Tyukanov, Metal Science and Heat Treatment 15 (1973) 332-334

[11] H. Yamaguchi, Y. Hisamatsu, Trans. Iron Steel Inst. Jpn 19 (1979) 649-658

[12] S. Dionne, G. Botton, M. Charest, F.A. Goodwin, study of interrupted galvannealing of Interstitials Free steels with different substrate compositions, E. Essadiqi, F. Goodwin, M. Elboujdani eds., Proceedings International Symposium on Materials in the Automotive Industry. Toronto, 2001, pp. 351-365

[13] T. Nakamori, CAMP - ISIJ 5 (1992) 1637-1640

[14] Y. Adachi, T. Nakamori, K. Kamei, J. Japan Inst. Metals 56 (1992) 1235-1241

[15] Z.W. Chen, R.M. Sharp, J.T. Gregory, Mater Sci. Technol. 6 (1990) 1173-1176

[16] E. McDevitt, Y. Morimoto, M. Meshii, ISIJ Int. 37 (1997) 776-782 